\title{
CLONING, EXPRESSION AND PURIFICATION OF AcrV TIP PROTEIN FROM Aeromonas hydrophila USING Escherichia coli HOST CELLS
}

\author{
Nguyen Van Sang*, Nguyen Thi Uyen
}

Faculty of Biology, VNU University of Science, Vietnam National University

Received 19 November 2020, accepted 15 March 2021

\begin{abstract}
Aeromonas spp. uses T3SS to secrete and transport effector proteins to the host cells. These proteins play a major role in bacteria virulence by interfering with the signaling cascades and disrupting the cytoskeleton structure of the host cell. Despite tremendous efforts, structural and functional information regarding AcrV tip protein of T3SS remains elusive. In this study, we cloned the gene encoding the AcrV protein from Aeromonas hydrophila AH-1 and inserted it into the pET-M expression vector. The pET-M vector containing AcrV gene was transformed and expressed in E.coli BL21 (DE3) cells. The recombinant AcrV protein was purified by affinity chromatography using Ni-NTA column. The obtained AcrV with high purity can be used for structural and functional studies.
\end{abstract}

Keywords: AcrV, Aeromonas hydrophila, affinity chromatography, gene expression, recombinant protein.

Citation: Nguyen Van Sang, Nguyen Thi Uyen, 2021. Cloning, expression and purification of AcrV tip protein from Aeromonas hydrophila using Escherichia coli host cells. Academia Journal of Biology, 43(1): 85-90. https://doi.org/10.15625/2615-9023/15686

*Corresponding author email: nvsangvnu@yahoo.com

C2021 Vietnam Academy of Science and Technology (VAST) 


\section{INTRODUCTION}

Aeromonas hydrophila is identified as a pathogen of fishes, reptiles, and amphibians (Shotts et al., 1972). During the last decade, A. hydrophila has gained its fame as more Aeromonas strains were found to be associated with a wide range of diseases in humans. Initially, Aeromonas strains were thought to be opportunistic pathogens feasting on immunocompromised patients. They are now known to be the cause of septicemia and many other gastrointestinal diseases in humans (Fiorentini et al., 1998; Thune et al., 1993). Type III secretion system (T3SS) is essential for $A$. hydrophila pathogenesis. By using T3SS, A. hydrophila can inject its effector proteins into the host-cell ( $\mathrm{Yu}$ et al., 2004). The three main components of T3SS are base, needle (composed of needle filament and tip complex), and translocon. Until now, the structure and function of proteins in T3SS have been considered and studied. However, the structure of the tip-complex remains elusive. It is crucial to determine the pathogenesis mechanism of bacteria, which will help develop effective drugs.

The tip complex which caps the needle filament plays a role in detecting host cells and sensing the environment (Epler et al., 2012). In the V-tip family protein (AcrV, PcrV, and LcrV), the structure of AcrV is still not available to date which limits our understanding about the function of this important protein. In Yersinia species, the assembly of translocator YopB-YopD pore is mediated by LcrV (Goure et al, 2005; Pettersson et al., 1999). The LcrV tip complex is predicted to be a pentameric ring, with LcrV protein being composed of $\mathrm{N}$-terminal globular domain, the coiled-coil region, and C-terminal globular domain (Lara-Tejero and Galan, 2019). In 2005, Mueller et al. showed that Aeromonas salmonicida and $P$. aeruginosa injectisome needles had a tip complex formed by PcrV and AcrV (Mueller et al., 2005). Finding the tip complex has clarified how the translocation pore is formed in the host cell membrane but the exact role of AcrV remains to be investigated. In this study, the AcrV gene was cloned from Aeromonas hydrophila AH-1 and expressed in E.coli BL21 (DE3) cells under the control of T7 promoter of $\mathrm{pET}-\mathrm{M}$ expression vector. The recombinant AcrV protein was purified by affinity chromatography. The research provides recombinant AcrV proteins of high purity, which can be used for structural and functional studies.

\section{MATERIALS AND METHODS}

The gene encoding AcrV was codonoptimized based on the AcrV gene sequence of A. hydrophila AH-1 (Accession No: AY394563.2). The codon - optimized sequence was chemically synthesized by Phusa Biochem (Can Tho, Vietnam). The pET-M expression vector was a modified product from pET32a, with the S-tag and theorin tag removed. The E.coli DH5- $\alpha$ and E.coli BL21 DE3 were cloning and expression host cells, respectively. Chemicals in this experiment were purchased from international companies, including Bio-rad, Sigma, Merck, Thermo scientific, and Serva in the United States or Germany.

\section{Construction of recombinant expression vector}

The gene encoding AcrV obtained from Phusa Biochem was amplified by PCR using forward primers AcrV-F gcGGATCCGAAATTAGCTCGTATAAAA AAGATCC with BamHI site and reverse primers AcrV-R cgGTCGACTTAAATCGCCTGCAGAATCT $\mathrm{G}$ with the SalI cleavage site. The PCR reaction used Phusion High-Fidelity DNA Polymerase (Thermo Scientific) according to the manufacturer's recommendations.

The PCR product and pET-M plasmid were digested by SalI and BamHI Fastdigest. For ligation DNA and vector, T4 DNA ligase of Thermo scientific was used. The ligated construct was then transformed into E.coli DH5alpha competent cells. PCR screening method was used to confirm the proper insertion of the AcrV gene into the plasmid vector. Colonies that contained DNA inserts of the correct sizes from the PCR screen were picked and cultured in LB environment with 
$100 \mu \mathrm{g} / \mathrm{ml}$ of ampicillin overnight. Subsequently, plasmids were extracted from E. coli cells using QIAGEN's Miniprep Kit kit. Plasmid products were sent for sequence analysis using the Sanger method at $1^{\text {st }}$ Base (Singapore).

\section{Expression of recombinant AcrV}

The pET-M-AcrV construct was transformed into E.coli BL21 (DE3). One single colony was then transferred into $10 \mathrm{ml}$ LB containing $100 \mu \mathrm{g} / \mathrm{ml}$ of ampicillin. $5 \mathrm{ml}$ of the overnight culture was inoculated into 1 $\mathrm{L}$ of LB containing $100 \mu \mathrm{g} / \mathrm{ml}$ of ampicillin and grown at $37^{\circ} \mathrm{C}$ with shaking until $\mathrm{OD}_{600}$ reached 0.6. IPTG (isopropyl $\beta-\mathrm{D}-1$ thiogalactopyranoside) was added to the culture at a final concentration of $0.3 \mathrm{mM}$. Cells were further grown at $25^{\circ} \mathrm{C}$ for 16 hours before harvesting by centrifugation for $10 \mathrm{~min}$ at $6000 \mathrm{rpm}$. The supernatant was discarded and the cell pellets were stored at $-20^{\circ} \mathrm{C}$ until purification.

\section{Purification of recombinant AcrV using affinity chromatography}

Cells pellets from $1 \mathrm{~L}$ of overnight culture were resuspended in $25 \mathrm{ml}$ of binding buffer (Tris-HCl $50 \mathrm{mM}$, pH 8.0; NaCl $300 \mathrm{mM}$; imidazole $5 \mathrm{mM}$ ). Cells were lysed by sonication on ice with $40 \%$ amplitude and for 6 rounds of $5 \mathrm{~min}$ each. The lysate was centrifuged for $30 \mathrm{~min}$ at $13000 \mathrm{rpm}$ and $4{ }^{\circ} \mathrm{C}$.

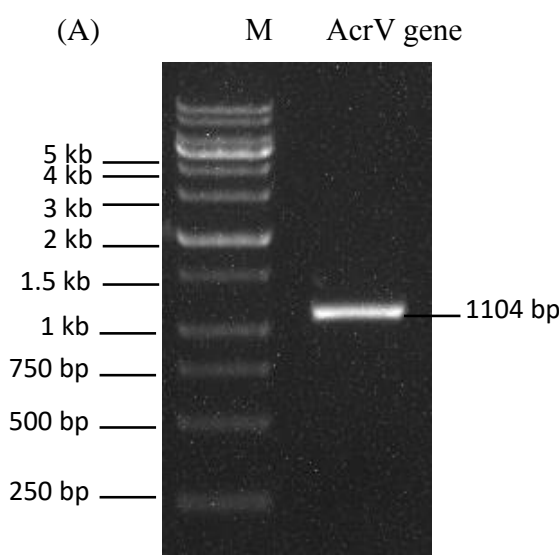

The supernatant was collected and loaded into Econo-column (Biorad) containing Ni-NTA bead pre-equilibrated with $20 \mathrm{ml}$ of binding buffer. The column was subsequently washed 10 rounds with binding buffer and 10 rounds with washing buffer (Tris- $\mathrm{HCl} 50 \mathrm{mM}, \mathrm{pH}$ 8.0; $\mathrm{NaCl} 300 \mathrm{mM} ; 30 \mathrm{mM}$ imidazole) to remove unbound proteins. The His-tagged proteins were eluted with $20 \mathrm{ml}$ of Elution buffer (Tris- $\mathrm{HCl} 50 \mathrm{mM}, \mathrm{pH} 8.0 ; \mathrm{NaCl} 300$ $\mathrm{mM}$; imidazole $400 \mathrm{mM}$ ). The eluted proteins were dialyzed overnight against $20 \mathrm{mM}$ Tris$\mathrm{HCl} \mathrm{pH} \mathrm{8.0,} 200 \mathrm{mM} \mathrm{NaCl}$ and concentrated to $15 \mathrm{mg} / \mathrm{ml}$, aliquoted into 1.5 eppendorf tubes, and stored at $-80{ }^{\circ} \mathrm{C}$.

\section{RESULTS AND DISCUSSION
Clonning of AcrV gene into pET-M expression vector

The AcrV gene was amplified using oligonucleotide primers containing BamHI and SalI restriction enzyme sites. The pUC19-AcrV plasmid template for PCR was chemically synthesized by Phusa Biochem. PCR result was shown in Figure 1A. The AcrV lane is a PCR product with only one $1104 \mathrm{bp}$ band corresponding to the size of AcrV gene. The AcrV PCR product was inserted into the pET-M expression vector. After screening, the plasmid pET-M-AcrV was extracted (Fig. 1 (B)) in lane 1, and then was sequenced by the Sanger method.

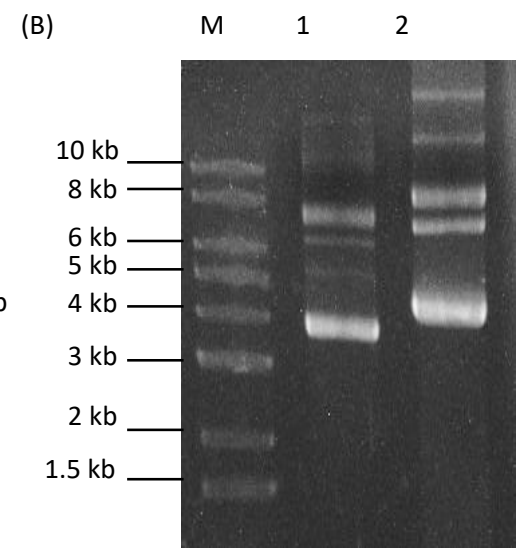

Figure 1. Cloning of AcrV gene into pET-M vector, (A) M: DNA marker 1kb; AcrV: AcrV gene was amplified from pUC-19-AcrV plasmid. (B) Result of plasmid extraction. (1): Plasmid pET-M, (2): Plasmid pET-M containing AcrV gene 


\section{Plasmid DNA sequencing}

The sequencing result of pET-M AcrV was translated into the amino acid sequence using Snapgene and compared with the amino acid sequences of AcrV from A. hydrophila AH-1 published in the GenBank (Accession
No: AY394563.2). The sequence comparison by CLUSTALW was presented in Fig. 2. These results indicated that the sequence was identical to the AcrV coding sequence. This confirms that we have succeeded in creating the expression vector carrying the AcrV gene.

\section{AcrV-Sequencing \\ МHHнHHHSSGLVPRGSMEISSYKKDPQLFLSDLGKVELNQLQGGSSSALDALVKLLQEKK 60 \\ AcrV-genbank -MEISSYKKDPQLFLSDLGKVELNQLQGGSSSALDALVKLLQEKK 44 \\ AcrV-Sequencing \\ IVITATYDKKIDSNPFADKVVTENEMLLKKVLAYFMPADSKNSGGQYDLQIKAGFEQLHK IVITATYDKKIDSNPFADKVVTENEMLLKKVLAYFMPADSKNSGGQYDLQIKAGFEQLHK $* * * * * * * * * * * * * * * * * * * * * * * * * * * * * * * * * * * * * * * * * * * * * * * * * * * * * * * * * * * * * * *$ \\ AcrV-Sequencing \\ LINEAAAAGKTKFTLREFLAATHFSLTPDRIDDDVIGAMLDAMGSHSSKRDTLKHEVGKL 180 \\ AcrV-genbank LINEAAAAGKTKFTLREFLAATHFSLTPDRIDDDVIGAMLDAMGSHSSKRDTLKHEVGKL

Figure 2. Amino acid sequence alignment of recombinant AcrV gene

AcrV-Sequencing: the amino acid sequence of AcrV was inserted into pET-M; AcrV- GenBank: the amino acid sequence of AcrV (Accession No: AY394563.2) was published in GenBank.

\section{Expression of AcrV in E. coli BL21 (DE3)}

AcrV was over-expressed in E. coli BL21 (DE3) cells with $0.3 \mathrm{mM}$ IPTG at $25{ }^{\circ} \mathrm{C}$. The AcrV expression result was analyzed by SDSPAGE electrophoresis (Figure 3). The results indicated that AcrV protein was only expressed with $42 \mathrm{kDa}$ band in IPTG-induced E. coli BL21 (DE3) harboring pET-M - AcrV (Fig. 3, lane AcrV+IPTG), while this band did not show in the control sample.

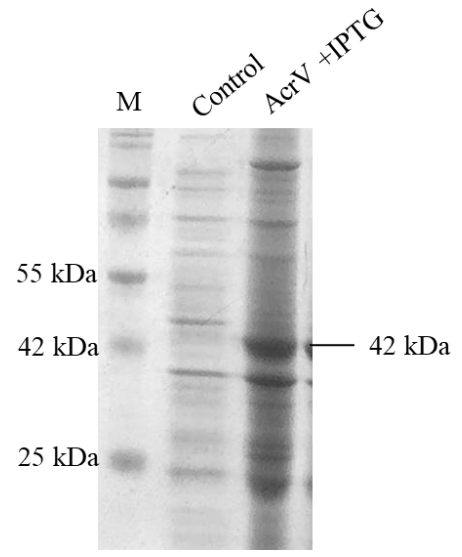

Figure 3. Expression of AcrV in E. coli DE3, M: Protein ladder; Control: non-induced cell; AcrV+IPTG: cells after IPTG induction 


\section{Purification of His-tag AcrV}

AcrV was expressed as a soluble His-tag protein in E. coli BL21 (DE3) cells. Cells were lysed by sonication. Ni-NTA beads were used to separate the His-tag protein from other bacterial proteins. SDS-PAGE result in Figure 4 showed that protein $6 x$ His- tag AcrV was purified with a thick specific band at $42 \mathrm{kDa}$ (lane 7 - Figure 4). The eluted protein was dialyzed against buffer containing $20 \mathrm{mM}$ Tris- $\mathrm{HCl} \mathrm{pH} 8.0,200 \mathrm{mM} \mathrm{NaCl}$ to remove imidazole from the elution buffer. Approximately $50 \mathrm{mg}$ of recombinant AcrV protein was obtained from one liter of LB culture. The purified protein was concentrated to $15 \mathrm{mg} / \mathrm{ml}$, aliquoted into microcentrifuge tubes, and stored at $-80{ }^{\circ} \mathrm{C}$.

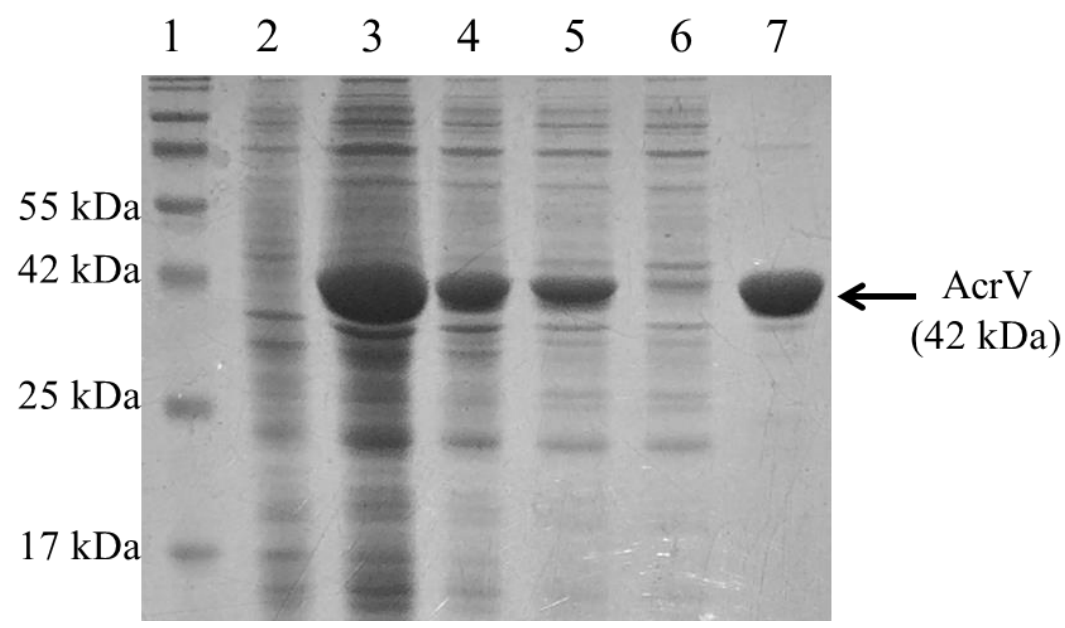

Figure 4. Purification of His-tag AcrV, 1: Protein ladder; 2: non-induced cell; 3: cell after IPTG induction; 4: cell pellet after sonication; 5: soluble protein after sonication; 6: flow-through from Ni-NTA affinity column; 7: eluted protein from Ni-NTA column

\section{CONCLUSION}

AcrV gene was cloned into pET-M vector and induced the expression in E. coli BL21 (DE3). Protein was expressed in LB medium at $25{ }^{\circ} \mathrm{C}$, induced by $0.3 \mathrm{mM}$ IPTG when $\mathrm{OD}_{600}$ reached 0.6 and harvested after 16 hours of induction. The recombinant AcrV tagged 6x-His had a molecular weight of 42 $\mathrm{kDa}$. Protein AcrV was purified with high purity by affinity chromatography with nickel bead. The obtained AcrV with high purity can be used for structural and functional studies.

Acknowledgements: This research is funded by Vietnam National Foundation for Science and Technology Development (NAFOSTED) under grant number 106-NN.02-2016.58.

\section{REFERENCES}

Epler C. R., Dickenson N. E., Bullitt E., Picking W. L., 2012. Ultrastructural analysis of IpaD at the tip of the nascent MxiH type III secretion apparatus of Shigella flexneri. Journal of molecular biology, 420: 29-39.

Fiorentini C., Barbieri E., Falzano L., Matarrese P., Baffone W., Pianetti A., Katouli M., Kühn I., Möllby R., Bruscolini F., 1998. Occurrence, diversity and pathogenicity of mesophilic Aeromonas in estuarine waters of the Italian coast of the Adriatic Sea. Journal of Applied Microbiology, 85: 501-511.

Goure J., Broz P., Attree O., Cornelis G. R., Attree I., 2005. Protective anti-V antibodies inhibit Pseudomonas and Yersinia translocon assembly within host membranes. The Journal of infectious diseases, 192: 218-225.

Lara-Tejero M., Galán J. E., 2019. The injectisome, a complex nanomachine for 
protein injection into mammalian cells, Protein Secretion in Bacteria, 245-259.

Mueller C. A., Broz P., Müller S. A., Ringler P., Erne-Brand F., Sorg I., Kuhn M., Engel A., Cornelis G. R., 2005. The Vantigen of Yersinia forms a distinct structure at the tip of injectisome needles. Science, 310: 674-676.

Pettersson J., Holmström A., Hill J., Leary S., Frithz-Lindsten E., Von Euler-Matell A., Carlsson E., Titball R., Forsberg A., Wolf-Watz H., 1999. The V-antigen of Yersinia is surface exposed before target cell contact and involved in virulence protein translocation. Molecular Microbiology, 32: 961-976.
Shotts Jr E., Gaines Jr J., Martin L., Prestwood A., 1972. Aeromonas-induced deaths among fish and reptiles in an eutrophic inland lake. Journal of the American Veterinary Medical Association, 161: 603.

Thune R. L., Stanley L. A., Cooper R. K., 1993. Pathogenesis of gram-negative bacterial infections in warmwater fish. Annual Review of Fish Diseases, 3: 37-68.

Yu H., Rao P. S., Lee H., Vilches S., Merino S., Tomas J., Leung K., 2004. A type III secretion system is required for Aeromonas hydrophila AH-1 pathogenesis. Infection and immunity, 72: $1248-1256$. 